\title{
Deporte y populismo: la fundación de una relación (Argentina, 1945-1955)
}

\author{
María Graciela RODRÍGUEZ
}

A pesar de haber sido históricamente evaluado por las ciencias sociales como una práctica "menor", las relaciones del deporte moderno con las instancias de elaboración de lo político permiten considerarlo como un lazo fuerte en donde leer la confluencia de las prácticas populares y la constitución de imaginarios sociales. Este trabajo se propone analizar las relaciones establecidas entre las estrategias políticoculturales populistas del primer peronismo (1945-1955) y la esfera deportiva, en tanto creemos que en ese periodo se configuran características particulares de la intersección deporte/política/cultura/medios; especialmente, la interpretación, reelaboración y negociación de los argumentos en torno de la nación.

Si bien los escenarios para esta operación son múltiples, la puesta en escena que los medios de comunicación masivos hacen del deporte permite que en esa textualidad pueda leerse una discursividad con retóricas, argumentos y teatralizaciones propias, que coexisten explosivamente con la expansión de las industrias culturales y los consumos de masas en dicho período. Entendemos que el estudio de este objeto permite inaugurar un aspecto nunca trabajado hasta ahora de las configuraciones político-culturales de nuestra sociedad. Y, aunque nuestro recorte es histórico, creemos que posibilita el establecimiento de hipótesis más amplias para comprender las disposiciones contemporáneas, en un escenario en que simultáneamente puede observarse una massmediatización globalizada y una "deportivización" de la agenda pública. 
Pensar esta relación desde una perspectiva cultural implica reconocer a los medios como "prácticas específicamente significantes" (Williams, 1981: 194) colocados en un sistema significante mayor, el de la cultura masiva, y reubicarlos en relación con el contexto estructural con el cual se vinculan. Estas relaciones, si bien no son lineales ni de mero reflejo de las condiciones objetivas, sí permiten el reconocimiento de cruces entre los consumos simbólicos y las lógicas económicas y políticas de las operaciones massmediáticas (Mata, M.C., 1991).

\section{LA "PATRIA" DEPORTIVA}

Entre 1945 y 1955, la Argentina vivió una época que puede considerarse de "fiesta deportiva". Durante la gestión peronista se produjo una serie de éxitos deportivos que fueron leídos como producto de una nacionalidad casi épica

1. Entre ellos, el triunfo en 1950 del seleccionado argentino sobre Estados Unidos en la final del Mundial de Básquet; los campeonatos sudamericanos de fútbol de 1946 y 1947; la medalla de oro ganada en la maratón por Delfo Cabrera en los Juegos Olimpicos de Londres en 1948; el triunfo de Domingo Marimón en el mismo año en la competencia automovilística "América del Sur" entre Buenos Aires y Caracas; la espectacular performance de Juan Manuel Fangio en Europa, quien en 1951 y 1954 obtuvo por dos veces el campeonato mundial de automovilismo; los Juegos

Panamericanos de 1951; los triunfos (que aún hoy se recuerdan) y que pasaron a formar parte del repertorio histórico de la Argentina ${ }^{1}$. Como también se recuerda la inversión y la gestión estatal que puso énfasis en la contribución al desarrollo del deporte comunitario a través de la promoción de los Torneos "Evita" y la construcción de complejos deportivos. Aunque la opinión que pesa sobre ellos es variada y se ofrece como un eje conflictivo de interpretación, lo que es un dato indudable del período es que, por primera vez en la historia, el Estado opera sobre el área, creando una modalidad de intervención innovadora con respecto a las anteriores administraciones gubernamentales.

Este trabajo centra su interés en las relaciones fundacionales que se establecen durante el populismo entre la industria cultural y los nuevos sujetos políticos que aquélla constituye como su público, tomando como eje las manifestaciones deportivas. Relación que no sólo puede rastrearse en las actuaciones comunitarias o escolarizadas sino también en la superficie textual de los productos culturales de la época, donde el deporte servía de puente hacia la construcción de una nueva referencialidad nacional.

La importancia que este período tiene para indagar en esta relación fundante reside en tres aspectos que aparecen como datos fuertes de estos años: la expansión del deporte (ya sea desde el punto de vista comunitario como el de alto rendimiento); el auge y la consolidación de la industria cultural que adquiere un fuerte rasgo intervencionista; y la irrupción en la esfera política de un nuevo actor social, las clases populares, llamado a ser el protagonista y el destinatario de las políticas de Estado. 
Esta aparición en escena de las clases populares y su nominación como "pueblo" define la interpelación populista como marco del período. Afirma Renato Ortiz (1992) que en Latinoamérica el populismo ha traducido la dualidad inherente a la cultura popular de ser fuerza y obstáculo del desarrollo, articulando las transformaciones sociales pertinentes a esta condición con los símbolos elegidos para representarlo, símbolos que pertenecen al dominio de la tradición. En el deporte, como uno de ellos, pueden leerse estas operaciones de reinterpretación de lo popular realizada no sólo por los diferentes grupos sociales sino también, y especialmente, por la propia construcción del Estado (Ortiz, 1985).

En esta línea, si bien el período 45-55 puede caracterizarse como "nacionalismo oficial" (Anderson, 1993) ${ }^{2}$, es necesario observar las tensiones existentes entre la necesidad de las clases dirigentes de marcar direcciones politicas y los repertorios y las gramáticas que la ciudadanía escoge para reinterpretar su sentido de pertenencia a una nación. Desde esta perspectiva, el concepto de ciudadanía aparecería como un concepto ampliado, es decir, como la adquisición de una cultura política a partir de prácticas diversas, no únicamente electorales o de militancia partidaria; por lo que 1945 puede considerarse un momento de emergencia participativa en el que se unifican la recuperación de derechos politicos perdidos con la obtención por primera vez de nuevos derechos civiles nunca antes conquistados, que responden a principios igualitarios y, por ende, legítimos.

En la Argentina de 1945 a 1955 el deporte sirvió para poner en escena (tanto en su práctica concreta como en el creciente nivel de los consumos audiovisuales) una teatralidad que, al tiempo que inauguraba el espectáculo deportivo como un nuevo ritual nacional posible (hasta ese momento prácticamente inimaginable por la sociedad política), ampliaba el repertorio simbólico común (García Canclini, 1991). Lo que interesa para este análisis es que el espectáculo deportivo aparecía por primera vez como válido para integrar el repertorio nacional y que su legitimidad estaba dada por su vínculo con lo popular. Desde allí se intentó organizar las energías dispersas en torno a repertorios colectivos de identidad.

La distancia entre la "memoria nacional", en tanto ideología e historia, y la "memoria colectiva", expresada en los mitos, la vivencia, los rituales, establece una tensión que será crucial para entender la fragilidad de la construcción de las identidades nacionales (Ortiz, 1985). De ahí la particular importancia que adquiere el conflictivo momento en que se del "Mono" Gatica; los campeonatos de box ganados por Pascual Pérez y Rafael Iglesias en sus respectivos pesos; los resultados en las pistas automovilísticas de los hermanos Gálvez; el Torneo Mundial de Ajedrez de Copenhague ganado por Oscar Panno; el triunfo en 1950 del equipo de polo de Venado Tuerto sobre un combinado estadounidense, etc.

2. Entendido como "artefacto cultural de una clase particular" que utiliza los aparatos del Estado para generar una idea de comunidad: educación primaria, obligatoria y masiva; propaganda estatal; revisión oficial de la historia (para recrear la "fundación de la patria"); militarismo; $\mathrm{y}$ otras acciones tendentes a la afirmación de la identidad nacional. 
funda la relación de los sectores populares y la creciente industria cultural con el deporte.

Y si el papel de los medios de comunicación en la construcción de las identidades nacionales se torna sumamente significativo, la escuela ocupa un rol privilegiado. Por lo tanto será necesario, junto con las áreas de la cultura y el deporte sobre las que el Estado intervino (sea directa o indirectamente), revisar también el papel jugado por la escuela en el desarrollo programático de la Educación Física y el deporte, para poder integrar el fenómeno al contexto mayor de aplicación de políticas estatales.

\section{UN NUEVO MAPA CULTURAL}

La fuerte expansión de la industria cultural, aunque ya venía operando sobre los nuevos sectores urbanizados, comenzó a conformar una relación dialéctica con sus audiencias. Los consumos culturales durante el populismo se constituyeron en un eje a partir del cual se interpeló a un público que encontraba en los productos culturales rasgos (estéticos, narrativos, de identificación, situacionales) que no sólo ponian en juego matrices culturales de reconocimiento sino también la apropiación de códigos, valores y procedimientos que se consideraban fundamentales para integrarse al proceso de participación democrática y cultural.

Por la necesidad de interpelar a este nuevo sector en donde confluían los rasgos más salientes de la ciudadanía a construir y del público ya conformado, el Estado peronista le atribuye una importancia decisiva al sistema de medios, diseñando una política intervencionista que será decisiva. En este período, la radio, ya sólidamente instalada en nuestro país, ubicará en la cultura de los sectores populares una práctica de consumo asociada al tiempo libre y al entretenimiento. Así, el acceso al consumo cultural pasa a formar parte de un "derecho", una necesidad reconocida que deviene de la posibilidad de usufructo de los bienes culturales que se ofrecen al mercado. La cultura popular poco a poco dejará de ser pensada al margen de la industria cultural.

Pese a las restricciones políticas, las transmisiones deportivas radiofónicas vivieron un momento de consolidación estilistica a partir del surgimiento de varios relatores deportivos que harian época: si ya en la década de los años treinta Lalo Pelicciari había seducido a las audiencias, en el decenio que nos interesa adquieren renombre las voces de Alfredo Arostegui, el "relator olímpico", Enzo Ardigó (quien populari- 
zó el término "evidentemente"), mientras que será el legendario Luis Elías Sojit quien impondrá un sello definitivo al estilo de transmisión deportiva radial (Ulanovsky y otros, 1995). En los soportes gráficos se daba una convivencia de medios estatizados y privados: la Empresa Editorial Haynes editaba Mundo Deportivo (con un régimen de propiedad que prácticamente dejaba a la empresa en manos del Estado) ${ }^{3}$. También se dedicaban al deporte El Gráfico, La Cancha, Goles (a partir de 1948), Coche a la Vista, de editoriales privadas. Entre los reporteros más destacados estaban Ricardo Lorenzo, "Borocotó", en El Gráfico, y Miguel Angel Merlo y "Billy Kerosene" (seudónimo de Ulises Barrera) en Mundo Deportivo.

Por otra parte, si bien los consumos culturales del periodo estaban en pleno auge, como lo indican tanto la consolidación del medio editorial, radiofónico y gráfico (Rivera, 1985) como el desarrollo de la industria cinematográfica ${ }^{4}$, la década comprendida entre 1945 y 1955 también es testigo de otra modificación en el rol del Estado cuya trascendencia se relaciona con uno de los fenómenos culturales más significativos del siglo: el ingreso de la televisión el 17 de octubre de 1951.

El escaso parque de receptores junto con la precariedad de las instancias de producción, hacen de este medio un dispositivo aún poco explotado en toda su potencialidad. Esto llevaria a desecharlo del análisis. Sin embargo, lo que es necesario destacar no es el medio en sí, sino la modalidad de intervención sobre él: contrariamente a lo sucedido con la radio, donde las primeras inversiones provinieron de los sectores privados, el nacimiento de la televisión en Argentina está fuertemente asociado a iniciativas del Estado.

$\mathrm{Si}$ por un lado se transforman sustancialmente los vínculos entre el ciudadano y el Estado, también se modifican los hábitos culturales, uno de los cuales estará marcado por el ingreso masivo de la televisión. Este nuevo soporte, sin sustituir los consumos instalados, viene a superponerse con aquéllos ya asentados como la gráfica, la radio o el cine. La televisión, más que reemplazar la relación, habrá de trocar las reglas del contrato de lectura modificando los hábitos culturales (perceptivos y de consumo) de los espectadores a lo largo del siglo y ubicándose en una serie de hitos sobre la modernización en la Argentina, más como un elemento de quiebre que de continuidad (Varela, 1994). En este sentido, un aspecto innovador, por oposición al cine, es su posibilidad de transmitir en simultáneo, lo que coloca a los eventos deportivos en el lugar de objeto de predilección. Dice Mirta Varela (Varela, 1994: 6):
3. Los vínculos del gobierno con esta empresa editorial no fueron sólo comerciales: en julio de 1949 se incorporó como vicepresidente $\mathrm{y}$ administrador Carlos Aloé, quien fuera entonces secretario administrativo de la Presidencia de la Nación y director y editorialista de Mundo Deportivo. En 1952 Aloé, al ser elegido gobernador de la provincia de Buenos Aires, fue reemplazado en el cargo de administrador por Antonio Nicoletti, aunque continuó dirigiendo la revista deportiva (Noguer, R., 1985).

\section{Entre 1945 y} 1955 se registró el récord en cuanto a promedio anual de films producidos en la Argentina: 42,7 películas anuales (Getino, O., 1995). Por otra parte, desde mediados de la década del treinta hasta aproximadamente 1956, la cinematografia nacional fue ganando las preferencias del mercado argentino, hasta convertirse en una sólida competidora de Hollywood y Europa (Rivera, J., 1985). 
Las cámaras se desplazarán reemplazando la acción que realizaría el sujeto al asistir a los acontecimientos transmitidos. Y entre estos últimos, los deportes ocupan un lugar privilegiado. Tanto la experiencia de la televisión norteamericana como el lugar que ocupan los deportes en la Argentina auguran -con razón- que televisión y deportes conformarán una buena pareja.

Aunque puede relacionarse el crecimiento de la producción cultural autóctona con el crecimiento económico del período, el apoyo estatal, que se expandió a prácticamente todas las industrias culturales, fue decisivo. Y el cine fue uno de los más beneficiados. Cabe citar aquí los productos audiovisuales con los cuales se escenificaban no sólo los logros deportivos de la Argentina en el exterior sino también la propia gestión de las políticas sociales en el área deportiva. En este sentido se debe centrar la atención en el cine como soporte paradigmático de la década, sobre todo por la gran expansión de esta industria cultural en esos años y su constitución como parte fundamental de la construcción del imaginario peronista.

De hecho, y para dar sólo un ejemplo del vasto repertorio, el mismo cine nos ofrece dos vertientes de análisis: por un lado, Sucesos Argentinos, noticiero cinematográfico que mostraba los resultados de la gestión deportiva, ya sea en el deporte comunitario y la expansión de las obras públicas (torneos infantiles, inauguración de polideportivos, etc.), como en la difusión de los logros de deportistas destacados. De ahí la relevancia que adquieren el estudio de los mitos referidos al éxito por la ruta del mérito, puestos en escena a través de las hazañas de los modernos héroes deportivos cuyo exponente acaso más mitificado sea el boxeador José María "Mono" Gatica. Por otro lado, los productos cinematográficos de ficción, que ponen en escena las relaciones del peronismo con las industrias y los agentes culturales, relaciones que no siempre muestran las apologías al régimen que se suponen propias de las gramáticas de producción durante el peronismo, aunque sí operarán, acaso oblicuamente, sobre la reinterpretación del nacionalismo.

De todos modos, la impronta estatizante del período puede observarse en toda la red massmediática, a partir de un plan intervencionista que ya se había iniciado en la etapa anterior y que culminó con la absorción de la mayoría de los medios de comunicación por parte del Estado. Por lo tanto, desde el punto de vista político, habrá que tener en cuenta el control ejercido por el peronismo sobre los medios en gene- 
ral (Ciria, 1983; Sirvén, 1984; Plotkin, 1994) y la legislación que le sirve de marco (Mastrini, G. y M. Abregú, 1990). En esta linea adquiere importancia el estudio de las relaciones entre las políticas estatales sobre el deporte y las politicas culturales en el período 1945-1955, porque puede ser pensado como un momento en el cual confluyen intervenciones estatales en varias áreas que darán marcos constitutivos al fenómeno deportivo tal como lo conocemos hoy.

\section{FÚTBOL "POPULAR"}

El caso del fútbol como práctica deportiva (y también indirectamente en relación hacia su espectacularización contemporánea) es especial: la consolidación que experimenta nuestro fútbol, a raíz de la permanencia en el país de los jugadores durante la posguerra, dura poco. Los carriles por los que venía circulando dicho deporte en la Argentina se enfrentaron, en este período, con algunos obstáculos que imposibilitan hablar de una fase serena. Y si el periodo a investigar dista mucho de ser una etapa pacífica en el ámbito del fútbol es justamente porque se trata del momento en que la profesionalización termina de consolidarse luego de una etapa que culmina con la huelga de 1948. Esta huelga es el último índice de la tensión en el fútbol acerca del debate entre deporte amateur y deporte profesional.

La entidad sindical que nucleaba a los jugadores de fútbol (Futbolistas Argentinos Agremiados, FAA) fue creada en 1944, 13 años después de la primera huelga protagonizada por futbolistas, luego de la cual se profesionalizaron los jugadores. Tras una serie de negociaciones entre jugadores y dirigentes, en julio de 1948, la primera fecha del Campeonato de Primera División fue suspendida por huelga, lo que provocó que ese año el campeonato nacional tuviera que jugarse con las divisiones inferiores. Las tensiones se prolongaron durante casi un año: mientras que los dirigentes apostaban a un retorno del amateurismo en el fútbol, los jugadores consiguieron, poco antes de iniciarse el campeonato de 1949, el reconocimiento oficial de la entidad sindical y la garantía del pago de sus haberes, junto a otros beneficios laborales entre los cuales estaba la libre contratación ${ }^{5}$.

Este conflicto (finalmente saldado a favor de los jugadores) es considerado por algunos analistas del caso como uno de los factores que incidieron en la diáspora de jugadores que, a partir de ese momento, se iba a generar en Argentina, re-
5. A la tensión que provocó el conflicto contribuyó también el apoyo de Evita a la causa de los trabajadores, lo que también causó el alejamiento del entonces presidente de la AFA, Óscar Nicolini, quien se había alineado en favor de los intereses de los dirigentes de los clubes (Scher, A. y H. Palomino, 1988). 
6. De los 105 jugadores que abandonaron el país en ese momento (muchos de ellos integrantes de la célebre "máquina" de River Plate que vivió sus días de fama y de gloria entre 1941 y 1947) la mayoría terminó jugando en las filas del fútbol de Colombia (Scher, A. y H. Palomino, 1988).

7. Scher, A. y H. Palomino, 1988, p. 79. forzada por la recuperación económica de los países europeos luego de la posguerra, así como de la reputación de excelencia ganada por el fútbol rioplatense en aquellos años ${ }^{6}$. Y si la Argentina no envió su seleccionado a los mundiales de fútbol de 1950 y de 1954, estas ausencias deben verse en su doble condición indiciaria: como carencia de jugadores, por las dificultades para armar un seleccionado, y como decisión politica, por temor a un fracaso estrepitoso.

Lo paradójico del caso del fútbol y que aporta un verdadero centro de atención a los efectos de este trabajo, es que en este período aumenta considerablemente el número de espectadores directos:

\begin{abstract}
El quinquenio 1946-1950 arrojó un promedio de 12.755 entradas vendidas por partido, en tanto que el de 19511955 registró uno de 12.685. Si se toman valores anuales, 1954, con 15.056 espectadores por encuentro, estableció la marca tope de un decenio en el que el promedio de asistencia jamás se redujo a menos de 10.000 asistentes $^{7}$.
\end{abstract}

Por su parte, Ernesto Goldar señala que en los vínculos del fútbol con el rugby, éste último aparece como una práctica diferenciadora de clase (Goldar, 1992), lo que revela la importancia del fútbol en la operación de constitución de un campo de producción massmediática dirigida a interpelar a los sectores populares. Este dato de por sí otorga una clave de entrada para analizar la relación que instituye el deporte entre los sectores populares y la industria cultural, relación que continuará, aún con transformaciones, reelaboraciones y reinterpretaciones de lo popular, de sus estéticas y de sus prácticas cotidianas.

\section{EL DEPORTE, ENTRE ESPECTÁCULO, ESTADIO Y ESTADO}

Para terminar, si, como afirma Bechelloni, el deporte transforma a los medios, los medios al deporte y ambos a la sociedad $^{8}$ (Bechelloni, 1995), el estudio de un momento como el que estamos analizando es decisivo en el establecimiento de esta relación y su desarrollo hacia la configuración de los vínculos en la cultura contemporánea. De alli que pueda considerarse el periodo como un momento fundacional de la constitución del deporte no sólo como práctica masiva sino también como práctica de un consumo cultural fuertemente signado por las instancias de producción del espectáculo. 
A estos efectos, pueden considerarse estas primeras intervenciones sobre el área del deporte y sobre el área de los medios de comunicación, como la confluencia de dos instancias que colaboraron en definir una relación entre las prácticas de consumo de los sectores populares y la industria cultural en donde se establecen las primeras reglas de su constitución. Los datos fuertes con respecto a las modificaciones en el consumo cultural del período, junto a los de una mayor distribución del ingreso, permiten sostener que en ese momento se dieron las condiciones para que las instancias de producción cultural operaran sobre un fenómeno: el deportivo, que si bien ya venía siendo objeto de una práctica masiva, aparece ahora como un objeto sobre el cual se puede intervenir efectivamente, tanto para los medios como para el Estado.

De ahí el interés de pensar al deporte como un fenómeno que, tanto por su labilidad como por su fortaleza, permite remitir a los argumentos nacionales para la construcción de un imaginario social que se estaba reelaborando. Las fuentes de esta construcción provienen tanto de los medios como de la propia experiencia de los sujetos, así como de las versiones que formula el Estado sobre la sociedad que gobierna y de otros discursos institucionales (de reproducción o alternativos) que circulan por el espacio público.

Si las identidades son el resultado impreciso de procesos conflictivos, su elaboración se realiza en torno a las significaciones que ciertas temáticas y operatorias adquieren para su vida cotidiana. De ahí que el deporte, y en especial el fútbol, facilita los vínculos de reconocimiento y afirmación colectiva. O, como afirma Javier Protzel, estos procesos oscilantes “(son) una parte del ser moderno" (Protzel, 1994: 57). Por lo tanto, la dimensión de las experiencias intersubjetivas se tornará crucial en torno a la relación entre el populismo y el consumo cultural del deporte, sobre todo teniendo en cuenta que en el decenio peronista se produce un fuerte incremento de asistencia a los estadios de fútbol.

Si el cruce politica, deporte y cultura parte de una concepción de cultura que abarca las manifestaciones simbólicas de una sociedad, entendidas como indices de sus condiciones materiales de producción, la tensión que se establece allí permite leer el fenómeno deportivo como cultura $\mathrm{y}$, por lo tanto, en su doble condición de reproductora de órdenes sociales y también como transformadora de los mismos. Más aún si sobre él operan politicas de intervención estatales. El deporte, en tanto mediación con la industria cultural, ha servido para generar procedimientos interpretativos 
que operaron sobre el imaginario nacional, ofreciéndose como un discurso apto para la renegociación de los significados públicos y la consiguiente viabilidad de una cultura.

Es así que se nos permite ingresar no sólo en la posibilidad de construir una perspectiva crítica desde la cual analizar las modalidades de espectacularización, sino también en la espinosa zona de las politicas culturales, educativas, deportivas y de comunicación, en el ámbito de la privatización creciente de los espacios públicos, el retroceso de los niveles de ciudadanía y la crisis del Estado. Y este recorrido posibilitaría una más profunda comprensión de los fenómenos sociales en general y de la zona dedicada al deporte y la cultura en particular. 
Bibliografía

Alabarces, P. y M.G. Rodríguez

1996

Cuestión de pelotas. Fútbol, deporte, sociedad, cultura. Buenos Aires: Atuel.

Anderson, B. 1993

Comunidades imaginadas. México DF: FCE.

Bechelloni, G.

1995

"Sport e media". Televisione come cultura (Cap. X). Nápoli: Liguore Editore.

Ciria, A.

1983

Politica y cultura popular: la Argentina peronista 1946-1955. Buenos Aires: La Flor.

García Canclini, N.

1991

Culturas hibridas: estrategias para entrar y salir de la modernidad, México DF: Grijalbo.

Gettino, O.

1995

Las industrias culturales en la Argentina. Dimensión económica y politicas públicas. Buenos Aires: Colihue.

Goldar, E.

1992

"El deporte". Vida cotidiana en la década del 50. Capítulo X. Buenos Aires: Plus Ultra.

Luna, F.

1991

Perón y su tiempo. Tomos I, II y III, Buenos Aires: Sudamericana.

Mastrini, G. y M. Abregú 1990

"Orígenes de la televisión privada argentina”, mimeo. 
Mata, M. C.

1991

"Memorias de la recepción. Aproximaciones a la identidad de los sectores populares". Diá-logos 30. Lima: Felafacs, junio.

Noguer, R.

1985

La radiodifusión en la Argentina. Buenos Aires: Ed. Bien Común.

Ortiz, R.

1985

Cultura brasileira \& Identidade nacional. San Pablo: Brasilense.

1992

"Cultura, espacio nacional e identidad". Ponencia en el VII Congreso de Felafacs. Acapulco, octubre de 1992. Traducción de Mirta Varela.

Plotkin, M.

1993

Mañana es San Perón. Buenos Aires: Espasa Calpe/Ariel.

Protzel, J.

1994

"Las multitudes del fútbol", en Diálogos 38. Lima: Felafacs, enero.

Rivera, J.

1985

"El auge de la industria cultural (1930-1955)". El escritor y la industria cultural. Buenos Aires: CEAL.

Scher, A. y H. Palomino 1988

Fútbol: pasión de multitudes $y$ de elites. Buenos Aires: Cisea.

Sirvén, P.

1984

Perón y los medios de comunicación. Buenos Aires: CEAL.

Ulanovsky, C. y otros 1995

Días de radio. Buenos Aires: Espasa Calpe.

Varela, M. 1994

"La creación de una cultura televisiva en la Argentina". Buenos Aires, mimeo.

Williams, R.

1981

Cultura. Sociología de la comunicación y del arte. Barcelona: Paidós. 